even a short growing period; it would be interesting to know whether under these conditions it lives for a greater number of years than those of its race which grow freely, and perhaps exhaust themselves producing seed. The water trickling from the snow-bed provides the damp environment favourable to it. One may unexpectedly find a small colony of harebells (Campanula) beneath the rocks perhaps two hundred yards from the snow-bed, but outside its normal influence. Snow-buntings are often seen near the snow; and for some years a blue hare had its home there, and my collie dog habitually put the animal up from boulder-strewn ground at almost always the same place. The animal may have found Gnaphalium supinum (a favourite plant with sheep) to its liking.

Fifty miles by air westward from Braeriach lies Ben Nevis, where a snow-field lies almost always unmelted beneath a high precipice which falls from the hill-top to the north-east. The surroundings of the snow-bed are sunless, dark and gloomy, and the rainfall there greatly exceeds that on Braeriach. The rocks which rise almost sheer above this snow-bed are higher than those which shelter the Braeriach snow-bed from the winds. I have mentioned that on Braeriach the sun in summer does shine for a time upon the snow, but I doubt if the Ben Nevis snow-field is lit up by sunshine at any time. The steep screes, which are unstable and easily provoked into a slide, are unfavourable to plant life, and with the exception of mosses and lichens on the stones there is no plant near the edges of the snow-bed except Saxifraga stellaris, which grows luxuriantly, although it has no time to form flowers. Its presence here is not without interest, as its seeds are almost certainly carried by the wind, perhaps also on the drifting snow during winter blizzards, from the edge of the plateau far above, where is to be found, at an elevation of $4,300 \mathrm{ft}$., the highest colony of this saxifrage in Britain. Indeed, the colony may be the highest of any phanerogam in the British Isles.

This account may fittingly be ended with a brief note on the possibility of perpetual snow existing in Britain. There are, as I have stated earlier, only two snow-beds which might be thought to be relies of the snow of the Ice Age. One of them is on Ben Nevis, the other on Braeriach. There have been rumours that in two years recently, when a mild winter was followed by a warm summer and autumn, the Ben Nevis snow-bed had disappeared. On Braeriach, it was reported to me that, about the year 1935, the snow had gone also. Yet when the Braeriach bed shrinks to its lowest ebb, it may well escape notice, as it recedes into a 'pocket' and becomes discoloured and ice-like in character. Indeed, on one occasion I reached a neighbouring 'pocket' and found it free of snow for the first time in my experience; and even then I was unable to see the bottom of the main 'pocket', although I was only a few yards from it. To my surprise, I found that the second 'pocket' still contained snow. There is, therefore, a possibility that this snow-bed is permanent; if so, it is the only perpetual snow in the British Isles.

Certain Highland families traditionally hold their land on the condition that they are able to supply the King with a bucket of snow whenever he should pass that way. The Camerons of Glen Nevis, the Graints of Rothiemurchus, and the Munros of Foulis are all supposed to hold their lands on this condition.

\section{CHEMICAL ASPECTS OF ATOMIC ENERGY}

$\mathrm{O}^{\mathrm{N}}$ $\mathrm{N}$ November 9 a symposium on "Chemical Aspects of Atomic Energy" was held in the University of Manchester. The meetings were arranged by the Manchester local section of the Chemical Society, in conjunction with the Society of Chemical Industry and the Royal Institute of Chemistry, and papers were presented by members of the staff of the Atomic Energy Research Estab. lishment.

In an introductory lecture, Dr. R. Spence (head of the Chemistry Division, Atomic Energy Research Establishment, Harwell) gave a broad survey of the role of the chemist in the atomic energy programme, and of the facilities for chemical research that have been set up at Harwell. After reviewing the development of the chemical effort from the time of the Tube Alloys Project, through the international co-operation at Montreal and later at the National Research Council laboratories at Chalk River, Ontario, he outlined the present organisation. In addition to the short-term problems that arise from the technological side of the work, there is need for a wide variety of fundamental research. Shorterterm work at Harwell includes technological investigations, the development of methods for extracting radio-isotopes of high specific activity and very high purity from materials irradiated in the British piles, and an extensive range of unusual analytical problems. For longer-term work, research groups are working in the fields of physical chemistry, with particular reference to ion exchange and the properties of concentrated solutions of electrolytes; radiochemistry, especially on problems related to the fission products; radiation chemistry (equipped with a 2-MeV. Van der Graaf generator, for producing monochromatic $\gamma$ - and $\beta$-radiation) and inorganic chemistry. The interests of these groups were reflected in the other papers of the symposium. As the chairman, Dr. F. Fairbrother, stated in his opening remarks, the work of the chemist enters in at every stage of pure and applied nuclear studies.

The place of the trans-uranic elements in the Periodic Table was discussed by Dr. J. S. Anderson. It has been unambiguously established that neptunium and plutonium have no similarity to rhenium and the platinum metals; we may infer that they belong to a transition series in which $5 f$, rather than $6 d$, electron-levels are being filled. We have to weigh the physical and chemical evidence to decide at what atomic number the $5 f$-levels first become tenanted, and to assign configurations to the known elements up to curium $(Z=96)$. Spectra of the heavy elements are complex; but Kiess and Meggers have assigned to uranium the ground-state $5 f^{3} 6 d 7 s^{2}$. Americium is said to have a simpler spectrum resembling europium; this would point to the ground-state $5 f^{7} 7 s^{2}$. The absorption spectra (for example, of UTV, PuVI, PuIV) rather resemble those of the rare earths and are suggestive of 'forbidden' transitions between $5 f$-levels. The magnetic moments of ions with effective atomic number ranging from 86 to $92\left(\mathrm{Ac}^{8+}, \mathrm{Th}^{\mathrm{s}}, \mathrm{U}^{\mathrm{B}}\right.$, $\mathrm{Am}^{2+}$ ) show a regular trend resembling that in the rare-earth series, but quantitative evaluation is not yet possible. Chemically, the most stable valence state changes regularly from uranium $\left(\mathrm{U}^{{ }^{+}+}\right)$, through neptunium $\left(\mathrm{Np}^{5+}\right)$, plutonium $\left(\mathrm{Pu}^{4+}\right)$ and americium $\left(\mathrm{Am}^{3+}\right)$ to the apparently constant trivalency of 
curium. 'Horizontal' relationships are clear between the oxy-cations $\mathrm{UO}_{2}{ }^{2+}, \mathrm{NpO}_{2}{ }^{2+}, \mathrm{PuO}_{2}{ }^{2+}$, and between the tetravalent states of all elements from thorium to plutonium or americium. Marshalling evidence from the solution chemistry and crystal chemistry of the halides, oxides, sulphides and phosphides of the heavy elements, with special reference to recent work on the lower valencies of thorium and the complex intermediate oxide phases of uranium, Dr. Anderson suggested that the following tentative conclusions can be drawn: thorium is the true analogue of zirconium and hafnium, that some $5 f$-levels are already tenanted in neutral uranium, and that the analogy of curium to gadolinium rests on suggestive, but incomplete, evidence. The practically unknown chemistry of protactinium leaves a gap at a most interesting point, and it is to be hoped that this may be remedied during the next few years.

Dr. E. Glueckauf, in a paper on the physical chemistry of solutions of uranyl nitrate, presented some new results on the constitution of such solutions and their partition equilibria with non-aqueous solvents. With solutions of concentration up to $2 M$, the activity coefficient of uranyl nitrate is higher than that of nitrates of other bivalent cations, but at bigher concentrations association to $\left[\mathrm{UO}_{2}\left(\mathrm{NO}_{3}\right)\right]^{+}$ and $\left[\mathrm{UO}_{2}\left(\mathrm{NO}_{3}\right)_{2}\right]$ occurs very markedly. The solutions are unique in the high partition coefficients for distribution of uranyl nitrate between water and esters, ethers, ketone and alcohols. In each type of solvent the solubility increases regularly with the oxygen/ carbon ratio, irrespective of the nature of the solvent -for example, ordinary ethers derived from aliphatic or cyclic radicals, poly-ethers (such as dibutyl cellosolve) or eyclic ethers such as dioxane. More. over, while the partition coefficients of nearly all divalent nitrates, between water and dibutyl tetraglycol, fall (on a relative scale) between 1 and 100, that of uranyl nitrate is $10^{5}-10^{6}$. In ethyl ether the difference is still greater, partition coefficients of cobalt nitrate, copper nitrate, and uranyl nitrate being in the ratio $1: 2: 10^{7}$. In the organic solutions, uranyl nitrate is mainly undissociated electrolytically and takes with it four molecules of water; the dissolved entity is $\left[\mathrm{UO}_{2}\left(\mathrm{NO}_{3}\right)_{2}\left(\mathrm{H}_{2} \mathrm{O}\right)_{4}\right]$. This information enables the partition equilibria in concentrated organic solutions to be treated quantitatively. From the organic solutions, solid complex compounds $\left[\mathrm{UO}_{2}\left(\mathrm{NO}_{3}\right)_{2}\left(\mathrm{H}_{2} \mathrm{O}\right)_{3}(S)\right]$ and $\left[\mathrm{UO}_{2}\left(\mathrm{NO}_{3}\right)_{2}\left(\mathrm{H}_{2} \mathrm{O}\right)_{2}(S)_{2}\right]$ ( $S=$ solvent molecule) have been isolated, and it is reasonable to formulate the known ammonium uranyl double nitrate as $\left(\mathrm{NH}_{4}\right)_{2}\left[\mathrm{UO}_{2}\left(\mathrm{NO}_{3}\right)_{4}\left(\mathrm{H}_{2} \mathrm{O}\right)_{2}\right]$. In the solid hexahydrate and its aqueous solutions, the complexes $\left[\mathrm{UO}_{2}\left(\mathrm{H}_{2} \mathrm{O}\right)_{6}\right]\left(\mathrm{NO}_{3}\right)_{2}, \quad\left[\mathrm{UO}_{2}\left(\mathrm{NO}_{3}\right)\left(\mathrm{H}_{2} \mathrm{O}\right)_{5}\right]$ $\left(\mathrm{NO}_{3}\right)$ and $\left[\mathrm{UO}_{2}\left(\mathrm{NO}_{3}\right)_{2}\left(\mathrm{H}_{2} \mathrm{O}\right)_{4}\right]$ probably exist. The $\left[\mathrm{UO}_{2}\left(\mathrm{NO}_{3}\right)\left(\mathrm{H}_{2} \mathrm{O}\right)_{5}\right]^{+}$ion differs in absorption spectrum from the $\left[\mathrm{UO}_{2}\left(\mathrm{H}_{2} \mathrm{O}\right)_{6}\right]^{2+}$ ion, suggesting that the nitrate ion may be covalently bound. The mechanism of such covalent binding, and of the remarkably strong solvation of the neutral complex by organic molecules, cannot be stated with certainty: Dr. Glueckauf outlined some hypotheses consistent with the present evidence.

Af F Morgan described recent advances in the chemistry o1 'ssion products, as shown in published American, Canadian and British work. One problem is that of the fission yield-the fraction of fissions giving rise to a particular mass number-in the different types of fission available for study. The yields of nearly all mass chains in the fission of uranium-236* (from the uranium-235-slow-neutron reaction) are now accurately known, though the distribution of nuclear charge is the subject of active work at Harwell and elsewhere. The shape of some fission yield curves are now well known; the ratio of the symmetrical mode of fission of uranium-235 to the most probable, asymmetric mode is about 1600 ; with uranium-233 and plutonium-239, asymmetric fission by thermal neutrons is also favoured. With sufficient deformation, most heavy nuclei undergo fission. Thus thorium-232 (threshold $1 \mathrm{MeV}$.) has been studied with different neutron energies; the ratio of symmetrical fission to most probable mode rises from $1 / 100$ for neutrons of $2 \mathrm{MeV}$. to $1 / 15$ for neutrons of 13-19 $\mathrm{MeV}$. A similar increase in symmetrical fissions is found by comparing the processes ${ }^{222} \mathrm{Th}+$ high-energy $\alpha$-particle $\rightarrow{ }^{236 *} \mathrm{U}$, with ${ }^{235} \mathrm{U}+{ }^{1}{ }_{0} n$ (thermal) $\rightarrow{ }^{236 * U}$. Finally, in the fission of bismuth-209 with $200-\mathrm{MeV}$. deuterons, the yield curve has a single symmetrical peak about mass $99-100$; the lighter fragments have a neutron excess, the heavier fragments being neutron-deficient $(\alpha$-active $)$ or stable. Knowledge of the neutroncapture cross-sections of fission products is important for the economic operation of piles. Such measurements involve either successive neutron-capture processes - the yield being measurable only if exceptional neutron fluxes are availablo-or the isolation of the fission products in carrier-free state. Physicochemical methods of separation-for example, by solvent extraction or ion-exchange processes-are particularly suitable, and lend themselves to use in shielded apparatus at high levels of activity. Individual rare-earths as well as the new elements 61 (promethium) and-especially interesting-43 (technetium) can be isolated from fission products by these means.

The last paper, on chemical effects of radiation, was given by Dr. W. Wild, under the chairmanship of Prof. M. G. Evans. The use of materials in and around the structure of a nuclear reactor is limited by radiation damage, while detailed studies of chemical effects are needed to provide the physicochemical background of biological studies. In a pile, fission fragments and $\beta$-radiation are largely absorbed within the fissile material, but moderator, coolant and structural material are subject to the effects of $\gamma$-radiation and fast neutrons. The primary effect of radiation is to excite or ionize molecules, the ejected electrons causing secondary ionization until they are slowed down and captured. The positive ion $\left(A^{+}\right)$may then undergo either decomposition (into radicals or stable molecules), reaction with other molecules, exchange of charge or neutralization by collision with a negative ion. Hence, the primary act. of excitation may initiate a series of chemical changes. The radiation decomposition of water is an important. reaction of this type, leading on long irradiation to evolution of hydrogen and oxygen, and the maintenance of a stationary concentration of hydrogen peroxide. The current view is that the initial process furnishes $\mathrm{H}_{2} \mathrm{O}^{+}$and electrons; the former react $\left(\mathrm{H}_{2} \mathrm{O}^{+}+\mathrm{H}_{2} \mathrm{O} \rightarrow \mathrm{H}_{3} \mathrm{O}^{+}+\mathrm{OH}\right)$ to give hydroxyl radicals, and the electrons lead ultimately to liberation of hydrogen-e $+\mathrm{H}_{2} \mathrm{O} \rightarrow \mathrm{H}_{2} \mathrm{O}^{-}, \mathrm{H}_{2} \mathrm{O}^{-} \rightarrow$ $\mathrm{OH}^{-}+\mathrm{H}$. In the absence of solutes, hydrogen and hydrogen peroxide result $\left(2 \mathrm{H} \rightarrow \mathrm{H}_{2}, 2 \mathrm{OH} \rightarrow \mathrm{H}_{2} \mathrm{O}_{2}\right)$; but in a closed system a stationary state is reached in which the back reaction proceeds by a chain mechanism- $\mathrm{OH}+\mathrm{H}_{2} \rightarrow \mathrm{H}_{2} \mathrm{O}+\mathrm{H}, \mathrm{H}+\mathrm{H}_{2} \mathrm{O}_{2} \rightarrow$ $\mathrm{H}_{2} \mathrm{O}+\mathrm{OH}$. In the presence of dissolved oxygen, hydrogen atoms react to form more hydrogen per- 
oxide. These reactions, and the effects of oxidizing and reducing ions in solution, can now be correlated with other studies of oxidation-reduction processes. In ionic solids, highly ionized atoms resulting directly from the collision of fast neutrons lose most of their energy by electronic excitation, but near the end of thoir track they must suffer elastic collisions. Atomic displacement and the rupture of chemical bonds thereby result, and the physical properties of solids are modified. A third field of radiation chemistry is in the study of 'hot-atom' chemistry - the ultimate chemical fate of atoms formed, often with high recoil energies, in nuclear reactions. To this category belong Szilard-Chalmers processes, and the formation of hydrogen cyanide, carbon monoxide and carbon dioxide, containing carbon-14, during the neutron irradiation of ammonium nitrate.

\section{J. S. ANDERSON}

\section{OBITUARIES}

\section{Dr. A. E. V. Richardson, C.M.G.}

THE death occurred in Melbourne on December 5, at the age of sixty-six, of Dr. A. E. V. Richardson, who for the last forty years has given distinguished service to the agricultural and pastoral industries of Australia. Born in Adelaide, Dr. Richardson's connexion with agriculture began when he was a student at Roseworthy Agricultural College. He studied science at the University of Adelaide, where he graduated M.A., B.Sc. In 1909 he was appointed assistant director of agriculture in South Australia, and in 1911 transferred to the Victorian Department of Agriculture as superintendent of agriculture. The purpose of his appointment was to put the activities of the Department on a scientific basis, and this was realized to the full. Richardson threw himself into his work with tremendous energy, and changed the whole basis of departmental advice from 'expert' opinion to the results of carefully planned experiments. He reviewed the scope of the State research farms and consolidated their work into three main stations: the Experiment Farm at Rutherglen, where work on the top dressing of pastures led to the establishment of subterranean clover throughout Victoria; the Central Research Farm at Werribee, working on cereal breeding; and Longerenong Agricultural College, which was responsible for the introduction of improved cultivation methods of wheat farming. As a result of his work, new wheat varieties were developed and many improvements made in wheat farming practice. Wheats developed from Werribee now represent 86 per cent of the acreage sown to this crop in Victoria. His publication "Wheat and its Cultivation" became a standard text on the subject in Australia, and for this work and research on the water requirements of farm crops he received in 1924 the first D.Sc. degree awarded in agriculture by the University of Melbourne.

In 1918 Richardson visited the United States and Canada for the Victorian Government to study agricultural education and research ; as a result of his report on this visit, the School of Agriculture was established on its present basis at the University of Melbourne, and Richardson was appointed dean of the Faculty and director of the School. He held these posts in addition to his position with the Department of Agriculture, and thus ensured a close link between the educational and research activities of the Univer- sity and the requirements of the Department for research and extension workers.

In 1924, Mr. Peter Waite, a prominent South Australian pastoralist, presented his estate on the outskirts of Adelaide, tngether with a considerable endowment, to the University of Adelaide, which, as a result, was able to establish the Waite Agricultural Research Institute and the Waite chair of agriculture. Richardson accepted an invitation to be first director of the Institute and occupant of the chair, and his energy, enthusiasm and devotion to the problems of agriculture found full scope in his new post. He was responsible for the development and expansion of the activities of the Waite Institute to its present leading position among the agricultural research institutes of Australia. In 1927 Richardson was appointed a member of the Executive Committee of the newly formed Council for Scientific and Industrial Research, a position he held until his retirement in 1949, and there is no doubt that his skilful judgment and wide knowledge of Australian agricultural problems contributed largely to the early success of the Council in selecting problems for research which yielded such valuable results for Australian primary industries. In 1938 he left the Waite Institute to become deputy chief executive officer of the Council for Scientific and Industrial Research, and in 1946, on the retirement of Sir David Rivett, he was appointed chief executive officer, a post which he hold until his retirement in 1949. In 1927 Richardson was a delegate to the first Imperial Agricultural Research Conference in London and in 1932 an official adviser to the Australian delegation to the Ottawa Conference. He was created C.M.G. in 1932. He was the first president of the Australian Institute of Agricultural Science in 1935, and in 1947 was president of the Australian and Now Zealand Association for the Advancement of Science. His presidential address, "Science in Relation to Australia's Development", is a brilliant survey of the possibilities of research in Australia.

Richardson was a big man, in mind and stature, and his genial, unassuming manner won him warm friends in many walks of life. Apart from his work he had wide interests, especially in the arts and in various games, in which he possessed greater than average ability. He had an encyclopædic knowledge of agricultural matters and a prodigious memory for facts and figures which made him a formidable opponent in argument. As well as his ability as an experimentalist and his unfailing judgment of the practical value of research, he possessed a capacity for solid work and careful attention to detail which made him such a successful administrator. $\mathrm{He}_{e}$ is survived by his wife and daughter.

\section{Prof. W. H. Newton}

Prof. Willuam Henry Newton, prefessor of physinlogy in the University of Edinburgh, dicd on December 20, after an illness of a few months. His all-too-early death makes a grievous gap in the ranks of British physiology.

Newton was born in 1904, the son of the Rev. J. T. Newton, and educated at Ashville College, Harrogate, and at the University of Manchester, taking firstclass honours in physiology at the B.Sc. examination in 1925. After a further year he took the M.Se. degree, and continued physiological studies (on plain muscle) during the succeeding three years, which were 